\title{
Effect of Gd implantation on the structural and magnetic properties of GaN and AIN
}

\author{
Sang Youn Han, J. Hite, G. T. Thaler, R. M. Frazier, C. R. Abernathy, and S. J. Pearton ${ }^{\text {a) }}$ \\ Department of Materials Science and Engineering, University of Florida, Gainesville, Florida 32611 \\ H. K. Choi, W. O. Lee, and Y. D. Park \\ School of Physics and Center for Strongly Correlated Materials Research, Seoul National University, \\ NS50, Seoul 151-747, Korea
}

J. M. Zavada

U. S. Army Research Office, Research Triangle Park, North Carolina 27709

R. Gwilliam

Surrey Ion Beam Center, University of Surrey, Guildford, Surrey GU2 7XH, United Kingdom

(Received 26 October 2005; accepted 1 January 2006; published online 23 January 2006)

$\mathrm{Gd}^{+}$ions were implanted at total doses of $3-6 \times 10^{14} \mathrm{~cm}^{2}$ into single-crystal $\mathrm{GaN}$ or AlN epilayers grown on sapphire substrates and annealed at $700-1000^{\circ} \mathrm{C}$. The implanted $\mathrm{Gd}$ showed no detectable diffusion in either material after annealing, as measured by secondary ion mass spectrometry, corresponding to a diffusion coefficient $<8 \times 10^{-12} \mathrm{~cm}^{2} \mathrm{~s}^{-1}$. Under all annealing conditions, x-ray diffraction shows the formation of second phases. In the case of GaN, these include $\mathrm{Gd}_{3} \mathrm{Ga}_{2}, \mathrm{GdN}$, and $\mathrm{Gd}$, while for AlN only Gd peaks are observed. Both the $\mathrm{GaN}$ and AlN show high saturation magnetization after annealing at $900{ }^{\circ} \mathrm{C}\left(\sim 15 \mathrm{emu} \mathrm{cm}^{-3}\right.$ for $\mathrm{GaN}$ and $\sim 35 \mathrm{emu} \mathrm{cm}^{-3}$ for AlN). The magnetization versus temperature characteristics of the Gd-implanted GaN show a blocking behavior consistent with the presence of precipitates, whereas the AlN shows a clear difference in field-cooled and zero-field-cooled magnetization to above room temperature which may also be due to Gd inclusions. (C) 2006 American Institute of Physics.

[DOI: 10.1063/1.2167790]

There is a strong interest in the properties of implanted rare-earth ions in wide band-gap nitrides for application in light-emitters and spintronics. ${ }^{1-15}$ The large band gaps of $\mathrm{GaN}$ and AlN allow exploitation of regions of the emission spectrum of some rare earths that are hidden in smaller bandgap host materials, and thus may have application in whitelight systems that employ either color combining or phosphor pumping. Gd-implanted AlN shows intense ultraviolet cathodoluminescence at $318 \mathrm{~nm},{ }^{1}$, while $\mathrm{Er}^{3+}, \mathrm{Eu}^{3+}, \mathrm{Tb}^{3+}$, $\mathrm{Yb}^{3+}$, and $\mathrm{Tm}^{3+}$ have also been investigated in this material, both for light emission and crystal-field splitting experiments on the high-energy states of the rare- earth ions. ${ }^{1,3,4,6,16-19}$ The most widely examined implanted rare-earth metal ion in $\mathrm{GaN}$ is $\mathrm{Er}^{3+}$ because of the interest in developing a temperature stable light emitter at $1.5 \mu \mathrm{m}$ for pumping of optical fiber. $^{4-11}$ The doping of nitrides with partially filled $4 f$ rareearth ions metals is also of interest as an alternative to transition metal doping for spintronics because of the possibility of above room-temperature ferromagnetism mediated either by carriers or by conduction through bands induced by the substitutional ions. Reports of Curie temperatures above $400 \mathrm{~K}$ and extremely large magnetic moments (much higher than the atomic moment) in Gd-doped $\mathrm{GaN}^{12-14}$ suggest that more understanding is needed of the behavior of this rareearth element in the wide band-gap nitrides. ${ }^{15}$

In this letter, we report on the structural and magnetic properties of GaN and AlN implanted with subamorphization doses of $\mathrm{Gd}$ at room temperature. In both cases, Gd-related phases appear after annealing and may contribute to the ob-

\footnotetext{
${ }^{a)}$ Electronic mail: spear@mse.ufl.edu
}

served magnetization, especially in the case of GaN.

The GaN samples were $\sim 3 \mu \mathrm{m}$ thick, Si-doped layers $\left(n \sim 10^{18} \mathrm{~cm}^{-3}\right)$ grown by metalorganic chemical vapor deposition on $c$-plane sapphire substrates at $1140{ }^{\circ} \mathrm{C}$. The undoped AIN layers were grown by rf-plasma-assisted molecular-beam epitaxy at $900{ }^{\circ} \mathrm{C}$ on $c$-plane sapphire substrates and were insulating $\left(>10^{6} \Omega \mathrm{cm}\right)$ as determined by Hall measurements. The samples were implanted using a HVEE $2 \mathrm{MV}$ ion implanter with Gd ions at two energies $(250$ and $500 \mathrm{keV})$ with doses of either $1.15 \times 10^{14}$ $(250 \mathrm{keV})$ plus $2.52 \times 10^{14}(500 \mathrm{keV}) \mathrm{cm}^{-2}$ or $2.3 \times 10^{14}$ $(250 \mathrm{keV})$ plus $5.4 \times 10^{14}(500 \mathrm{keV}) \mathrm{cm}^{-2}$. The samples were held near room temperature during the implantation, which was performed with typical beam currents of $0.1 \mu \mathrm{A} \mathrm{cm}^{-2}$. From visual inspection, the implanted regions were not amorphous under our conditions, as expected from

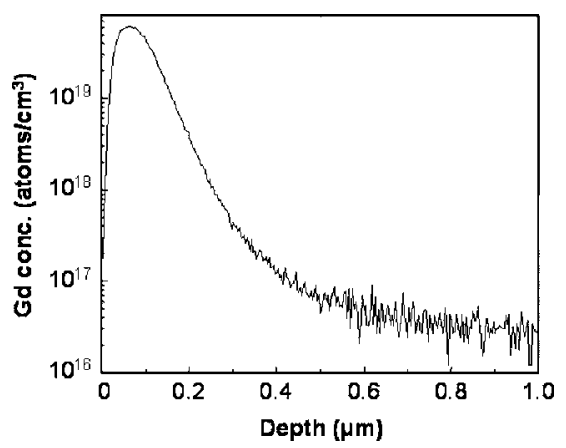

FIG. 1. SIMS profile of $\mathrm{Gd}$ implanted into $\mathrm{GaN}$ at $250 \mathrm{keV} / 2.3$ $\times 10^{14} \mathrm{~cm}^{-2}$ and $500 \mathrm{keV} / 5.4 \times 10^{14} \mathrm{~cm}^{-2}$. 


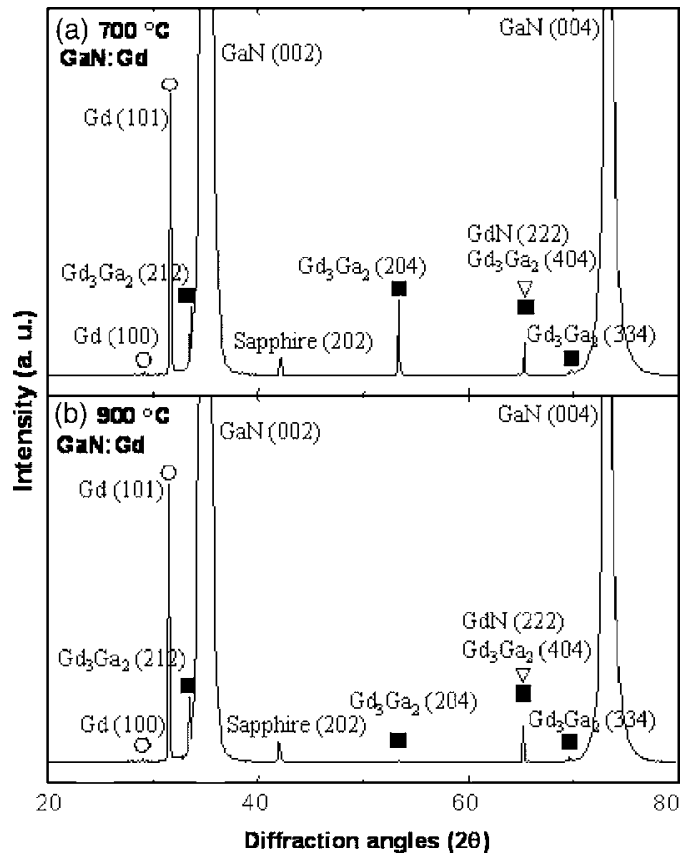

FIG. 2. XRD spectra from Gd-implanted $\mathrm{GaN}\left(250 \mathrm{keV} / 2.3 \times 10^{14} \mathrm{~cm}^{-2}\right.$ and $500 \mathrm{keV} / 5.4 \times 10^{14} \mathrm{~cm}^{-2}$ ) annealed at either (a) $700{ }^{\circ} \mathrm{C}$ and (b) $900{ }^{\circ} \mathrm{C}$.

previous reports by Kucheyev et al..$^{20-24}$ on the temperature, dose, and dose rate dependence of amorphization in nitrides. Annealing was performed for 5 min under flowing $\mathrm{N}_{2}$ gas at temperatures of $700-1000^{\circ} \mathrm{C}$ for $\mathrm{GaN}$ and $900{ }^{\circ} \mathrm{C}$ for AlN. Powder x-ray diffraction (XRD) was used to determine the phase composition of the films. Magnetic behavior of the Gd-implanted films and their unimplanted companions was investigated using a Quantum Design Magnetic Properties Measurement System superconducting quantum interference device magnetometer. Magnetization versus applied field and magnetization versus temperature measurements were taken up to the limit of the sample holder $(\sim 350 \mathrm{~K})$. Background effects were subtracted from the raw data and the subsequent data were normalized to volume to ensure proper comparison between films.

Figure 1 shows the secondary ion mass spectroscopy (SIMS) profile from the as-implanted GaN sample (total dose $7.7 \times 10^{14} \mathrm{~cm}^{-2}$ ). The projected ranges determined by SIMS were consistent with the values expected from a stopping-and-range-of-ions-in-matter (SRIM) simulation. ${ }^{25}$ No significant redistribution of the $\mathrm{Gd}$ could be determined in either nitride at $1000^{\circ} \mathrm{C}(\mathrm{GaN})$ or $900{ }^{\circ} \mathrm{C}(\mathrm{AlN})$. Based on the experimental depth resolution of $\sim 100 \AA$, this translates to an effective diffusivity of $<8 \times 10^{-12} \mathrm{~cm}^{2} \mathrm{~s}^{-1}$ for $\mathrm{Gd}$ in the two materials at the highest anneal temperatures used for each.

Figure 2 shows the XRD spectra from the GaN implanted with $\mathrm{Gd}$ at a total dose of $7.7 \times 10^{14} \mathrm{~cm}^{-2}$ and annealed at either $700{ }^{\circ} \mathrm{C}$ (top) or $900{ }^{\circ} \mathrm{C}$ (bottom). In both cases, there are second phases present; namely, $\mathrm{Gd}_{3} \mathrm{Ga}_{2}$, $\mathrm{GdN}$, and Gd. Based on the best available information on the heat of formation of these compounds ${ }^{26,27}$ and previous reports from Xiao et al. ${ }^{28}$ on the reaction of $\mathrm{Gd}$ with $\mathrm{GaN}$, it is expected that the reaction $\mathrm{Gd}+\mathrm{GaN} \rightarrow \mathrm{Ga}+\mathrm{GdN}+\mathrm{Ga}_{x} \mathrm{Gd}_{y} \mathrm{~N}$ will occur, and that the Ga can then form alloys of $\mathrm{Gd}_{x} \mathrm{Ga}_{y} .{ }^{27}$ Clearly, the Gd may then be present in a number of forms within the $\mathrm{GaN}$ and not simply as substitutional dopant oc-

are remotely possible include superparamagnetism and spin-
cupying the Ga site.
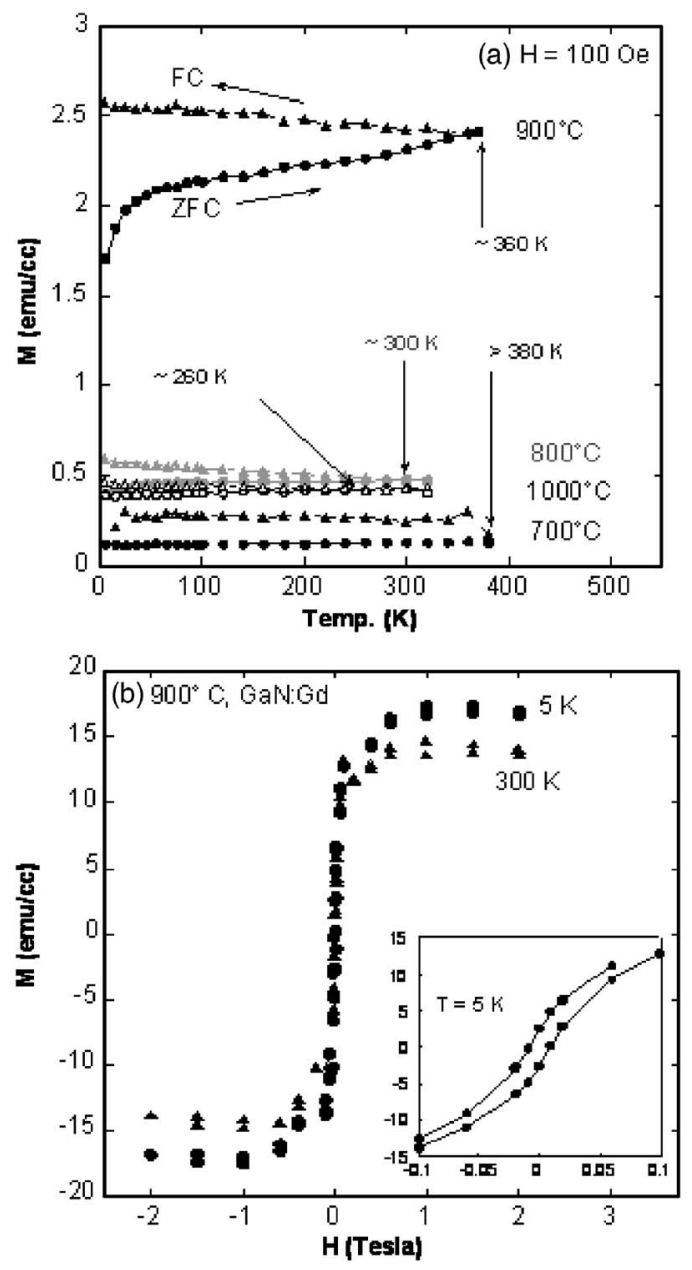

FIG. 3. (a) FC/ZFC magnetization measurements with each $T_{B}$ labeled for Gd-implanted $\mathrm{GaN}$ annealed at different temperatures $(H=100 \mathrm{Oe})$ and $(\mathrm{b})$ $\mathrm{M}$ vs $\mathrm{H}$ at 5 and $300 \mathrm{~K}$ for the sample annealed at $900^{\circ} \mathrm{C}$.

The magnetic properties of $\mathrm{Gd}$-implanted $\mathrm{GaN}$ are summarized in Fig. 3. The plots on the top show all of the zerofield-cooled (ZFC)/field-cooled (FC) measurements of various annealed samples implanted with $3.67 \times 10^{14} \mathrm{~cm}^{-2}$ total dose. We express magnetization as emu/cc using the SIMS profile calibration of $\mathrm{Gd}$ incorporation distance. The $900{ }^{\circ} \mathrm{C}$ anneal is optimal in terms of total magnetization. The lower anneal temperatures may produce a lower magnetization through incomplete annealing of the implant damage. Previous reports have shown the importance of crystalline quality in achieving strong magnetization in transition metal-doped nitrides ${ }^{29}$ Higher anneal temperatures may lead to loss of $\mathrm{Gd}$ from solution. An interesting feature is the change in the "blocking temperature" $\left(T_{B}\right)$ or where ZFC/FC curves meet. If we interpret the $T_{B}$ as arising from superparamagnetic precipitates, we would expect the $T_{B}$ to increase with annealing temperature as precipitates increase in size. However, we observe the opposite behavior, from the lowest to the highest annealing temperatures considered, which may possibly suggest a more favorable formation of non-magnetic Gd-rich alloys at higher annealing temperatures as well as loss of $\mathrm{Gd}$ from solution. Figure 3 (bottom) shows the magnetization $(M)$ versus field behavior $(H)$ at 5 and $300 \mathrm{~K}$ for $\mathrm{Gd}-$ implanted samples annealed at $900{ }^{\circ} \mathrm{C}$. Hysteretic behavior is clearly observed, consistent with ferromagnetism. Other possible explanations for hysteretic $M$ versus $H$ behavior that are remotely possible include superparamagnetism and spinto AIP license or copyright; see http://apl.aip.org/apl/copyright.jsp 

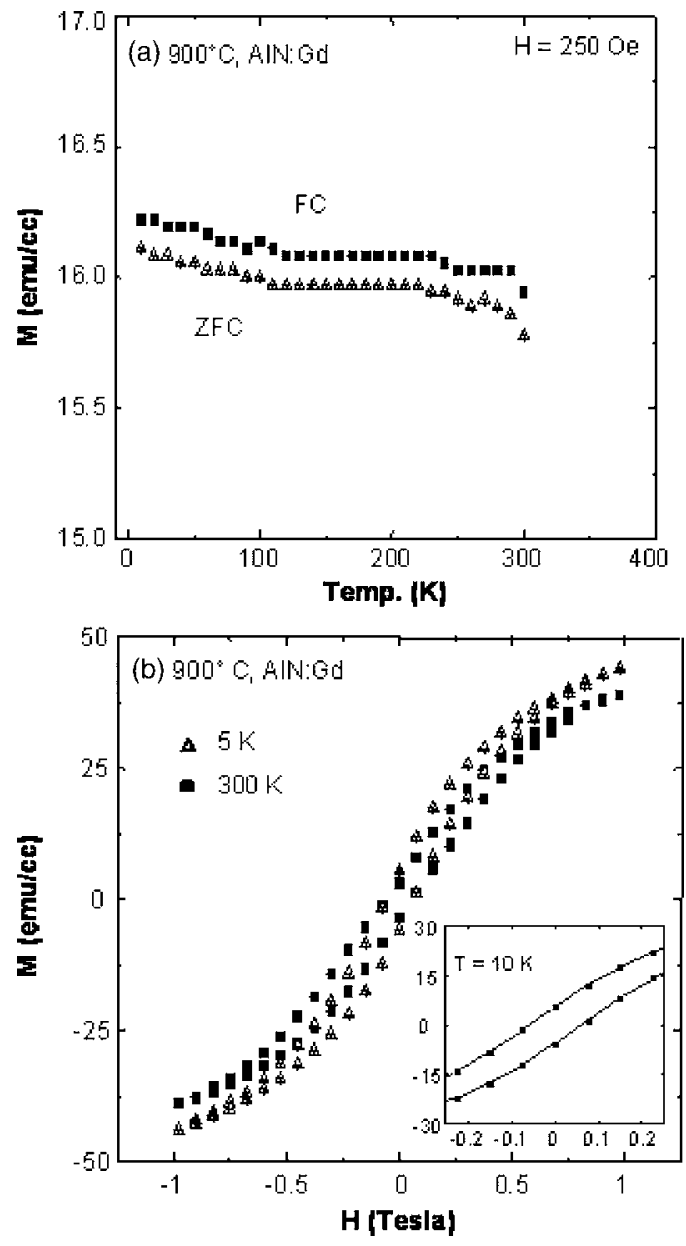

FIG. 4. (a) FC/ZFC magnetization from Gd-implanted AlN annealed at $900{ }^{\circ} \mathrm{C}$ and (b) $\mathrm{M}$ vs $\mathrm{H}$ at 5 and $300 \mathrm{~K}$ for the same sample.

glass effects as $T_{B}$ for the particular sample is found to be $\sim 360 \mathrm{~K}$. Magnetization measurements were also performed on the unimplanted $\mathrm{GaN}$ samples to eliminate the possibility that spurious transition metal impurities might be responsible for the magnetic response. These exhibited no magnetic hysteresis, showing that the Gd doping is responsible for the observed magnetization. Bulk Gd is a ferromagnetic material with Curie temperature of $308 \mathrm{~K}$, while rocksalt-phase $\mathrm{GdN}$ is also ferromagnetic with $T_{C}$ of $72 \mathrm{~K}$. The observed magnetic properties may come from Gd precipitates which are likely to have a different Curie temperature than bulk Gd or from the $\mathrm{Gd}_{3} \mathrm{Ga}_{2}$, whose magnetic properties are not known. We also cannot rule out a contribution from a true GaGdN alloy component.

The XRD spectrum from Gd-implanted AlN annealed at $900{ }^{\circ} \mathrm{C}$ showed only $\mathrm{Gd}$ in addition to the AlN peaks. The formation of $\mathrm{Gd}_{x} \mathrm{Al}_{y}$ compounds is less energetically favored in the $\mathrm{Gd}+\mathrm{AlN}$ system relative to their $\mathrm{Gd}_{x} \mathrm{Ga}_{y}$ counterparts. ${ }^{26,27}$ The magnetic data from the Gd-implanted AlN are shown in Fig. 4. Once again the magnetization shows a difference between the FC and ZFC plots to above room temperature and clear hysteretic behavior at $300 \mathrm{~K}$. Dhar et $a l .{ }^{13}$ suggested that Gd causes a long-range polarization of the GaN matrix, while Dalpain and Wei ${ }^{15}$ suggested from theory that electron doping was needed to stabilize fer- romagnetism in Gd-doped nitrides. Of course, our AlN is insulating and does not contain a significant concentration of carriers. Future work should investigate whether altering the implantation temperature can reduce the tendency for Gd to remain out of solution after annealing. It is critical for most potential spintronic applications that a true dilute magnetic semiconductor forms with polarized carrier population.

The work at UF was partially supported by NSF-DMR 0400416 and by the U.S. Army Research Office under Grants Nos. ARO DAAD 19-01-1-0710 and DAAD 19-02-1-0420, and by AFOSR F49620-03-1-0370.

${ }^{1}$ U. Vetter, J. Zenneck, and H. Hofass, Appl. Phys. Lett. 83, 2145 (2003). ${ }^{2}$ U. Vetter, M. Reid, R. Wegh, S. Soverna, and A. Meijerink, Mater. Res. Soc. Symp. Proc. 743, 231 (2003).

${ }^{3}$ J. B. Gruber, U. Vetter, H. Hofsass, B. Zandi, and M. F. Reid, Phys. Rev. B 69, 195202 (2004).

${ }^{4}$ R. G. Wilson, R. Schwartz, C. R. Abernathy, S. J. Pearton, N. Newman, M. Rubin, T. Fu, and J. M. Zavada, Appl. Phys. Lett. 65, 992 (1994).

${ }^{5}$ X. Wu, U. Hommerich, J. D. MacKenzie, C. R. Abernathy, S. J. Pearton, R. Schwartz, R. G. Wilson, and J. M. Zavada, Appl. Phys. Lett. 70, 2126 (1997).

${ }^{6}$ X. Wu, U. Hommerich, J. D. MacKenzie, C. R. Abernathy, S. J. Pearton, R. G. Wilson, R. N. Schwartz, and J. M. Zavada, J. Lumin. 72, 284 (1997).

${ }^{7}$ S. J. Pearton, C. R. Abernathy, J. D. MacKenzie, R. G. Wilson, R. N. Schwartz, and J. M. Zavada, Appl. Phys. Lett. 71, 1807 (1997).

${ }^{8}$ E. Alves, M. F. da Silva, J. C. Soares, J. Bartels, R. Vianden, C. R. Abernathy, and S. J. Pearton, MRS Internet J. Nitride Semicond. Res. 451, G11-2 (1999).

${ }^{9}$ A. J. Steckl and J. M. Zavada, MRS Bull. 24, 33 (1999).

${ }^{10}$ A. J. Steckl, J. C. Heikenfeld, D. S. Lee, M. J. Garter, C. C. Baker, Y. Wang, and R. Jones, IEEE J. Sel. Top. Quantum Electron. 8, 749 (2002).

${ }^{11}$ K. Lorenz, U. Wahl, E. Alves, S. Dalmasso, R. W. Martin, K. P. O’Donnell, S. Ruffenach, and O. Briot, Appl. Phys. Lett. 85, 2712 (2004).

${ }^{12}$ N. Teraguchi, A. Suzuki, Y. Nanishi, Y. K. Zhou, M. Hashimoto, and H. Asahi, Solid State Commun. 122, 651 (2002).

${ }^{13}$ S. Dhar, O. Brandt, M. Ramsteiner, V. F. Sapega, and K. H. Ploog, Appl. Phys. Lett. 94, 037205 (2005).

${ }^{14}$ H. Asashi, Y. K. Zhou, M. Hashimoto, M. S. Kim, X. J. Lin, S. Emura, and S. Hasegawa, J. Phys.: Condens. Matter 16, S5555 (2004).

${ }^{15}$ G. M. Dalpian and S.-H. Wei, Phys. Rev. B 72, 115201 (2005).

${ }^{16} \mathrm{H}$. Ennen and J. Schneider, J. Electron. Mater. 14, 115 (1985).

${ }^{17}$ A. Steckl and R. Birkhahn, Appl. Phys. Lett. 73, 1700 (1998).

${ }^{18} \mathrm{~K}$. Gurumurugan, M. Chen, G. Harp, W. Jadwisienczak, and H. Lozykowski, Appl. Phys. Lett. 74, 3008 (1999).

${ }^{19}$ W. Jadwisienczak, H. Lozykowski, I. Berishev, A. Bensaoula, and I. Brown, J. Appl. Phys. 89, 4384 (2001).

${ }^{20}$ S. O. Kucheyev, J. S. Williams, C. Jagadish, J. Zou, and G. Li, Phys. Rev. B 62, 7510 (2000).

${ }^{21}$ S. O. Kucheyev, J. S. Williams, C. Jagadish, J. Zou, V. S. J. Craig, and G. Li, Appl. Phys. Lett. 77, 1455 (2000).

${ }^{22}$ S. O. Kucheyev, J. S. Williams, J. Zou, C. Jagadish, and G. Li, Appl. Phys. Lett. 78, 1373 (2001).

${ }^{23}$ S. O. Kucheyev, J. S. Williams, A. I. Titov, G. Li, and C. Jagadish, Appl. Phys. Lett. 78, 2694 (2001).

${ }^{24}$ S. O. Kucheyev, J. S. Williams, J. Zou, C. Jagadish, M. Pophristic, S. Guo, I. T. Ferguson, and M. O. Manasreh, J. Appl. Phys. 92, 3554 (2002).

${ }^{25}$ Courtesy of J. M. Ziegler.

${ }^{26}$ Handbook on the Physics and Chemistry of Rare Earths, edited by K. A. G. Schneider, Jr. and L. R. Eyling (North-Holland, Amsterdam, 1979), Vol. 2.

${ }^{27}$ Binary Alloy Phase Diagrams, edited by T. B. Massalski (ASM International, Metals Park, OH, 1992).

${ }^{28}$ W. Xiao, Q. Guo, Q. Xue, and E. G. Wang, J. Appl. Phys. 94, 4847 (2003).

${ }^{29}$ G. Thaler, R. Frazier, B. Gila, J. Stapleton, M. Davidson, C. R. Abernathy, S. J. Pearton, and C. Segre, Appl. Phys. Lett. 84, 2578 (2004). 